\title{
Os efeitos da Lei de Responsabilidade Fiscal no endividamento dos municípios do Piauí
}

\author{
Fabricio Linhares \\ Caen/UFC \\ Christiano Penna \\ DTE/UFC \\ Glenda Borges \\ Caen/UFSC
}

A Lei de Responsabilidade Fiscal (LRF) procura, em seu bojo, imprimir a austeridade na efetivação dos gastos públicos. Sua finalidade é equilibrar os gastos públicos imprimindo em seu contexto uma nova perspectiva fiscal. Este artigo aplica uma modificação da metodologia proposta por De Jesus Macedo e Corbari (2009) para avaliar os efeitos da LRF no endividamento municipal, tendo como base de dados os municípios do estado do Piauí. Posto que a LRF foi implantada em 2000, o objetivo do artigo é verificar se houve alteração no endividamento municipal a partir da implementação dessa lei. O estudo sugere que os municípios piauienses reduziram sua dívida em aproximadamente $7 \%$ após a implementação da LRF.

Palavras-chave: Lei de Responsabilidade Fiscal; gasto público; endividamento; município.

\section{Los efectos de la Ley de Responsabilidad Fiscal en el endeudamiento de los municipios de} Piauí, Brasil

La Ley de Responsabilidad Fiscal (LRF) busca, a su paso, imprimir la austeridad en la efectuación de los gastos públicos. Su finalidad es equilibrar los gastos públicos imprimiendo en su contexto una nueva perspectiva fiscal. Esto artículo aplica una modificación de la metodología propuesta por De Jesus Macedo y Corbari (2009) para evaluar los efectos de la LRF en el endeudamiento municipal, teniendo como base de datos los municipios del estado de Piauí, Brasil. Dado que la LRF fue implantada en 2000, el objetivo del artículo es verificar se hubo cambio en el endeudamiento municipal desde la implementación de esa ley. El estudio sugiere que los municipios de Piauí redujeron su deuda en aproximadamente un 7\% después de la implementación de la LRF.

Palabras clave: Ley de Responsabilidad Fiscal; gasto público; endeudamiento; municipio.

Artigo recebido em 27 set. 2012 e aceito em 4 set. 2013. 
Effects of the Fiscal Responsibility Law on the indebtedness of towns in Piauí, Brazil

The Fiscal Responsibility Law (LRF) seeks, in its core, to imprint austerity in the effectuation of public spending. Its purpose is balancing public spending by imprinting in its context a new fiscal perspective. This article applies a change to the methodology proposed by De Jesus Macedo and Corbari (2009) to evaluate the effects of LRF on municipal indebtedness, based on data from the towns of the state of Piauí. Given that the LRF was implemented in 2000, the aim of this article is checking whether there was a change in the municipal indebtedness since this law was implemented. The study suggests that the towns in Piauí reduced their debt by about 7\% after the implementation of LRF.

Keywords: Fiscal Responsibility Law; public spending; indebtedness; municipality.

\section{Introdução}

O endividamento do setor público, a exemplo da própria União, é verificado quando as receitas não são suficientes para cobrir as despesas; a palavra que predominou por muitos anos no cenário das administrações públicas foi o déficit. Contudo, a partir da Constituição Federal de 1988, mecanismos com propostas eficientes vêm paulatinamente sendo criados e utilizados para reverter esta situação.

Historicamente, as regiões mais pauperizadas do país, como a região Nordeste, vêm observando um constante endividamento de seus municípios. Essa situação se configurou principalmente até o início da década de 2000, em que os governos sucessivamente acumulavam meses de déficits, caracterizando um problema de governo e de estado.

No entanto, a partir de maio de 2000, a intitulada Lei de Responsabilidade Fiscal (LRF) buscou impor limites ao endividamento público e a vários outros aspectos das finanças públicas. Essa Lei fixou limites para despesas com pessoal e para a dívida pública, além de determinar que fossem elaboradas metas para o controle de receitas e despesas. Como consequência ao cumprimento destas normas, era de se esperar que houvesse um ajuste fiscal que levasse a uma maior disponibilidade de recursos a serem aplicados na melhoria dos serviços públicos e a uma redução do déficit fiscal.

A LRF estipulou para estados e municípios um limite superior para gastos com pessoal em 60\% da receita corrente líquida. Para evitar o endividamento excessivo, uma Resolução do Senado Federal (40/2001) estipulou uma relação de 1,2 entre a dívida consolidada líquida e a receita corrente. Além disso, também foram definidas metas fiscais anuais e a exigência de apresentação de relatórios trimestrais de acompanhamento, estabelecendo, ainda, mecanismos de controle das finanças públicas em anos eleitorais e proibindo o socorro financeiro cedido pela União aos estados e municípios, além de estabelecer punições, caso tais normas não fossem cumpridas.

Esta imposição de limites seria, portanto, um grande avanço trazido não apenas para o saneamento eficaz das finanças da União, dos estados e dos municípios, como também para a realização de um ajuste fiscal definitivo, indispensável ao crescimento econômico sustentável, à geração de renda e ao bem-estar social. 
Especificamente para o caso brasileiro, uma série de estudos buscou analisar o efeito desta Lei nas finanças públicas de entes públicos, principalmente em nível municipal. ${ }^{1}$ Costa (2008), por exemplo, discute os efeitos da LRF para a redução do endividamento das 26 capitais estaduais do Brasil e sugere que a LRF não se confirma como um mecanismo institucional para a redução do endividamento público, havendo evidências de que o teto do endividamento estava bem acima do endividamento corrente das cidades brasileiras. O trabalho também sugere que a LRF foi criada apenas para controlar os municípios mais endividados, dos quais São Paulo se destaca com o mais alto endividamento.

O trabalho de Veloso e Teixeira (2007) buscou verificar se a LRF foi eficiente e qual foi seu impacto sobre os municípios do estado do Rio Grande do Sul. A partir da análise de variáveis fiscais, eles buscaram verificar a abrangência e os limites da lei quanto ao comportamento da despesa e, em particular, sua implicação sobre o comportamento de gastos com pessoal.

De Jesus Macedo e Corbari (2009) analisaram de que forma a LRF, como mecanismo de restrição fiscal, influenciou o padrão de endividamento praticado pelos municípios brasileiros com mais de 100 mil habitantes. Seus resultados indicam que as variáveis Estrutura de Capital e Endividamento Defasado alteraram o padrão de comportamento do endividamento público no decorrer dos anos 1998-2006.

Santolin, Jayme Jr. e Reis (2009) realizaram um estudo dos possíveis impactos da Lei de Responsabilidade Fiscal no comportamento das despesas dos municípios de Minas Gerais. Para tanto, foram analisados cenários anteriores e posteriores da LRF, com base nos quais se comparou o comportamento das prefeituras municipais em relação às suas políticas de gastos. Inicialmente, foi identificada uma convergência da despesa com pessoal nos municípios mineiros. Além disso, verificou-se também um processo de convergência dos gastos com investimento. Este estudo utilizou uma metodologia econométrica um pouco mais rebuscada que as demais, baseada em painel dinâmico. A análise sugere que este processo de convergência dos gastos com investimentos esteve associado à convergência e à ampliação dos gastos de pessoal, por um lado, e, por outro, pelas restrições de operações de crédito impostas pela LRF.

Apresentando algumas estatísticas descritivas, Fioravante, Pinheiro e Vieira (2008) revelam que a grande maioria dos municípios da região Nordeste apresenta gastos com pessoal relativamente moderados (a média de gastos de sete entre os nove estados que compõem esta região é inferior à média nacional), entretanto, nota-se um grande número de municípios que, entre 1998 e 2000, ultrapassaram o limite de 60\% de gastos com pessoal como proporção da receita corrente líquida. Na análise destes autores, o estado do Piauí exerce uma posição de destaque: analisando os períodos 1998-2000 e 2001-04, “com a exceção do estado do Piauí, a média de gastos de todos os estados aumentou após a implementação da lei” (Fioravante,

\footnotetext{
${ }^{1}$ Há uma vasta literatura internacional, tanto teórica quanto empírica, que versa sobre o impacto de leis sobre o endividamento de unidades subnacionais. O trabalho de De Jesus Macedo e Corbari (2009) cobre essa literatura de modo bem apropriado.
} 
Pinheiro e Vieira, 2008:71); ou seja, a Lei de Responsabilidade Fiscal parece, definitivamente, ter exercido o efeito esperado neste estado.

Uma pergunta de interesse que surge neste contexto é: qual foi o real efeito da Lei de Responsabilidade Fiscal nos municípios piauienses? O presente trabalho busca responder a esta pergunta com base nas modelagens econométricas sugeridas por Costa (2008) e De Jesus Macedo e Corbari (2009). Tal modelagem tem como variável dependente o endividamento público e, como variáveis preditoras, o endividamento defasado, a estrutura de capital, a liquidez, o grau de dependência, as despesas com pessoal e as despesas com investimento; sendo possível analisar qual o efeito destas variáveis no nível de endividamento dos municípios piauienses através de uma dummy temporal que fixa o momento da implementação da LRF.

Os capítulos remanescentes deste trabalho abordam, após esta introdução, os fatores capazes de influenciar o endividamento, os dados e a metodologia aqui empregada, os resultados e discussões e, por fim, as conclusões finais dos autores. Como de praxe, as referências bibliográficas são apresentadas ao final do trabalho.

\section{Fatores que influenciam no endividamento}

A promulgação da LRF teve como uma de suas principais causas promover o controle da dívida pública brasileira. A sustentabilidade da LRF reside, então, em planejamento governamental, responsabilização, transparência e controle. A LRF é, portanto, uma das respostas aos problemas de disciplina fiscal e às contingências do déficit e do endividamento, enfrentadas pelos entes públicos.

Devido a isso, o planejamento governamental, com bases no Plano Plurianual de Investimentos (PPA), na Lei de Diretrizes Orçamentárias (LDO) e a na Lei Orçamentária Anual (LOA), passa a ser de extrema relevância para a efetividade das políticas fiscais.

Uma das principais preocupações dos analistas de políticas repousa sobre a possibilidade de os municípios cumprirem o teto estabelecido pela Lei. Santolin e colaboradores (2009) ressaltam que

Estudos empíricos como Fiovarante et al. (2006), Menezes (2005) e Giuberti (2005) (...) identificaram um "erro de calibragem" na imposição de $60 \%$ da despesa com pessoal como proporção da receita, dado que apenas uma minoria dos municípios brasileiros ultrapassava esse teto. Neste sentido, a imposição de um limite superior estimulou o aumento desse tipo de despesa para a maioria dos municípios que apresentavam gastos muito inferiores ao teto. Os motivos que causaram este comportamento dos gastos, abordados pelos autores supracitados, são variados, mas podem ser resumidos pelo comportamento oportunista do político.

Em se tratando da região Nordeste, um esboço desta elevação de gastos pode ser visto por meio das estatísticas descritivas apresentadas em Fioravante e colaboradores (2006), na tabela 1, a seguir. 
Tabela 1

Estatísticas descritivas - despesa com pessoal/receita

\begin{tabular}{|lcccc|}
\hline \multicolumn{1}{|c}{ Estado } & $\begin{array}{c}\text { Média } \\
(1998-2000)\end{array}$ & $\begin{array}{c}\text { Desvio-padrão } \\
(1998-2000)\end{array}$ & $\begin{array}{c}\text { Média } \\
(2001-04)\end{array}$ & $\begin{array}{c}\text { Desvio-padrão } \\
(2001-04)\end{array}$ \\
\hline Maranhão & 0.3678 & 0.1180 & 0.3976 & 0.0768 \\
Piaú & 0.3777 & 0.1114 & 0.3713 & 0.0798 \\
Ceará & 0.4019 & 0.0929 & 0.4057 & 0.0706 \\
Rio Grande do Norte & 0.3722 & 0.1067 & 0.4034 & 0.0688 \\
Paraíba & 0.3964 & 0.0882 & 0.4270 & 0.0719 \\
Pernambuco & 0.4792 & 0.1006 & 0.4772 & 0.0670 \\
Alagoas & 0.3929 & 0.0881 & 0.4140 & 0.0709 \\
Sergipe & 0.4439 & 0.0863 & 0.4591 & 0.0652 \\
Bahia & 0.3923 & 0.1135 & 0.4031 & 0.0673 \\
Nordeste & 0.3998 & 0.1087 & 0.4133 & 0.0766 \\
Brasil & 0.4266 & 0.2228 & 0.4201 & 0.0730 \\
\hline
\end{tabular}

Fonte: Fioravante e colaboradores (2006).

Os autores que apresentaram os dados ainda ressaltam que,

com a exceção do estado do Piauí, a média de gastos de todos os estados aumentou após a implementação da lei. Esse comportamento mostra como a imposição de uma política de controle de gastos, quando se estabelecem metas irrealistas para o contexto em questão, gera efeitos distorcidos, como no caso, o aumento dos gastos.

Parece-nos, portanto, que a LRF parece ter logrado o resultado esperado no estado do Piauí, pelo menos no que se trata da proporção despesa com pessoal/receita corrente líquida. Entretanto, essa não é a única variável que influencia o endividamento municipal. O estudo de Menezes (2005) realiza um levantamento sobre o endividamento dos municípios brasileiros e sugere que: i) a LRF atingiu o objetivo de diminuir a despesa total dos municípios, atenuando sua tendência de crescimento real; ii) a partir da edição da referida lei, a receita apresentou crescimento superior ao da despesa, resultando em superávit constante; iii) a despesa corrente foi reduzida, mas em decorrência de outras despesas correntes, pois as despesas com pessoal aumentaram; $i v$ ) as despesas com investimentos foram reduzidas; $v$ ) as despesas de caráter social, que apresentavam tendência de crescimento, foram atenuadas pela LRF; vi) as despesas com overhead (Legislativo e planejamento) e com infraestrutura apresentaram forte queda em virtude da lei.

A análise de Menezes (2005) também revela que as variáveis políticas influenciam no aumento ou na diminuição dos gastos municipais, dependendo do quadro político estruturado. Os pontos levantados em Menezes (2005) nos remetem ao estudo de De Jesus Macedo e 
Corbari (2009). Visando mensurar o efeito da LRF nos municípios brasileiros com mais de 100 mil habitantes, esses autores selecionam indicadores de gestão financeira, selecionados a partir dos indicadores fiscais preconizados pela LRF, e, posteriormente, avaliam o efeito destes indicadores de gestão financeira sobre o endividamento municipal. As variáveis selecionadas, sua formulação, bem como a relação esperada com o endividamento, são descritas a seguir.

\section{Dados e metodologia}

\subsection{Dados}

Com base em rubricas municipais, De Jesus Macedo e Corbari (2009) constroem seis indicadores de gestão financeira capazes de influenciar o endividamento municipal. As rubricas necessárias para a construção desses indicadores são: Passivo Permanente (PP); Passivo Financeiro (PF); Ativo Financeiro (AF); Ativo Total (AT); Receita Corrente Líquida (RCL); Transferências (TR); Receita Total (RT); Gastos com Pessoal, Encargos com Pessoal e Gastos com Investimentos. Essas rubricas foram obtidas através do sistema Finanças do Brasil (Finbra), disponível em banco de dados Access baixado do site: <www.stn.fazenda.gov.br>. Os indicadores sugeridos pelos autores são os que se seguem na tabela 2 .

Tabela 2

Indicadores de gestão financeira e sua relação com o endividamento

\begin{tabular}{|c|c|c|}
\hline Indicador & Descrição da variável & Relação com endividamento \\
\hline Endividamento passado & & Positiva \\
\hline Estrutura de capital & & Positiva \\
\hline Liquidez & & Negativa \\
\hline Grau de dependência & & Positiva \\
\hline Despesas com pessoal & & Positiva \\
\hline Despesas com investimento & & Positiva \\
\hline
\end{tabular}

Fonte: Adaptado de De Jesus Macedo e Corbari (2009) apud Matias e Campelo (2000).

O endividamento é uma variável de estoque e indica a proporção da Receita Corrente Líquida necessária para se cobrir as dívidas em que se incorreu até então. É de se esperar que o montante de dívidas passado influencie o montante de dívidas correntes, daí a inclusão do Endividamento passado como variável explicativa.

A variável estrutura de capital indica o montante de capital de terceiros que está sendo utilizado pela administração pública para exercer suas funções; a liquidez é igual à parcela das obrigações que podem ser saldadas com recursos próprios disponíveis; o grau de dependência evidencia a dependência municipal em relação a recursos de outras esferas governamentais; a 
variável despesa com pessoal indica a parcela da receita corrente comprometida com despesas de pessoal; a despesas com investimento busca captar se os investimentos realizados por meio de operações de crédito de longo prazo vêm ampliando o endividamento municipal.

A relação que se espera encontrar do endividamento com as demais variáveis é a de que as despesas com investimento e com pessoal, o grau de dependência, a estrutura de capital e o endividamento defasado tenham uma relação positiva com a variável dependente. Ao contrário das demais variáveis, espera-se que liquidez possua uma relação negativa com o endividamento.

Visto que os estudos anteriores apontam para um efeito positivo da LRF, pelo menos para o estado do Piauí, seria interessante, portanto, mensurar qual o real efeito dessa lei no endividamento municipal. De Jesus Macedo e Corbari (2009) sugerem que isto pode ser feito com base em uma análise utilizando uma dummy temporal para a LRF, que assume valor zero, caso a LRF não tenha sido implementada, e valor um, caso a lei estivesse vigorando. ${ }^{2}$

Nesse sentido, coletaram-se dados no sítio do Tesouro Nacional e montou-se um painel de dados com os indicadores de gestão financeira, conforme sugerem De Jesus Macedo e Corbari (2009). Tais indicadores requerem uma série de dados que nem sempre são informados pelos municípios; como resultado, há várias observações faltando ao se computar tais indicadores. Foi feito o seguinte: (i) havendo apenas uma observação faltando para um determinado ano, a mesma foi preenchida através da média da variável nos dois anos mais próximos; (ii) havendo dois ou mais missing values consecutivos, por exemplo, não havendo uma variável para o ano de 2000 e de 2001, optou-se por retirar esse município da amostra.

Aplicada essa regra, houve uma drástica redução da amostra de municípios: o painel de dados ficou composto de 83 municípios piauienses que compreendeu o período de 1998 a 2007. Entre estes municípios, nenhum deles foi desmembrado durante o período em análise e todos os dados foram deflacionados para R\$ de 2007 a partir do IPCA.

As estatísticas descritivas da média municipal das variáveis para cada período (antes e depois da implementação da LRF) são expostas a seguir.

Tabela 3

Estatísticas descritivas dos indicadores

\begin{tabular}{|lcccccc|}
\hline & \multicolumn{2}{c}{ Endividamento } & \multicolumn{2}{c}{ Estrutura de capital } & \multicolumn{2}{c|}{ Liquidez } \\
\hline & $1998-2000$ & $2001-07$ & $1998-2000$ & $2001-07$ & $1998-2000$ & $2001-07$ \\
Média & 0.590 & 0.479 & 1.197 & 1.189 & 3.730 & 5.936 \\
Erro-padrão & 0.036 & 0.019 & 0.017 & 0.016 & 1.274 & 1.636 \\
Mediana & 0.523 & 0.449 & 1.154 & 1.151 & 1.214 & 2.560 \\
Desvio-padrão & 0.326 & 0.176 & 0.156 & 0.149 & 11.608 & 14.901 \\
\hline
\end{tabular}

${ }^{2}$ A LRF passou a vigorar a partir de 2000, ou seja, nossa variável é: $D_{t}^{L R F}=\left\{\begin{array}{l}0, \text { caso } t \leq 2000 \\ 1, \text { caso } t>2000\end{array}\right.$ 


\begin{tabular}{|lcccccr|}
\hline & \multicolumn{2}{c}{ Endividamento } & \multicolumn{2}{c}{ Estrutura de capital } & \multicolumn{2}{c|}{ Liquidez } \\
\hline Variância & 0.106 & 0.031 & 0.024 & 0.022 & 134.743 & 222.044 \\
Curtose & 0.733 & 4.018 & 2.988 & 5.464 & 63.587 & 52.737 \\
Assimetria & 0.962 & 1.176 & 1.425 & 2.012 & 7.610 & 6.771 \\
Intervalo & 1.517 & 1.175 & 0.861 & 0.843 & 101.576 & 125.771 \\
Mínimo & 0.072 & 0.093 & 1.003 & 1.025 & 0.098 & 0.250 \\
Máximo & 1.588 & 1.269 & 1.864 & 1.869 & 101.674 & 126.022 \\
Soma & 48.982 & 39.784 & 99.311 & 98.707 & 309.595 & 492.695 \\
\hline & Dependência & & Pessoal & & Investimento \\
\hline & $1998-2000$ & $2001-07$ & $1998-2000$ & $2001-07$ & $1998-2000$ & $2001-07$ \\
Média & 0.972 & 0.946 & 0.360 & 0.378 & 0.221 & 0.149 \\
Erro-padrão & 0.004 & 0.003 & 0.011 & 0.007 & 0.011 & 0.005 \\
Mediana & 0.982 & 0.949 & 0.356 & 0.377 & 0.213 & 0.138 \\
Desvio-padrão & 0.040 & 0.032 & 0.103 & 0.066 & 0.101 & 0.049 \\
Variância & 0.002 & 0.001 & 0.011 & 0.004 & 0.010 & 0.002 \\
Curtose & 23.768 & 29.837 & 0.605 & 0.456 & 0.065 & 1.097 \\
Assimetria & -4.353 & -4.480 & -0.334 & 0.442 & 0.608 & 0.928 \\
Intervalo & 0.289 & 0.258 & 0.592 & 0.322 & 0.437 & 0.252 \\
Mínimo & 0.710 & 0.723 & 0.012 & 0.229 & 0.042 & 0.052 \\
Máximo & 0.999 & 0.981 & 0.604 & 0.552 & 0.479 & 0.304 \\
Soma & 80.670 & 78.522 & 29.902 & 31.351 & 18.318 & 12.388 \\
\hline
\end{tabular}

Fonte: Elaboração dos autores.

No tocante ao endividamento dos municípios piauienses, uma coisa chama a atenção. Ao se observar o comportamento dessa variável nos dois períodos em análise (antes e depois da LRF), constata-se uma redução do endividamento médio dos municípios ( 0.59 contra 0.479) e uma drástica redução da variância em torno da média (0.106 contra 0.031).

Do que trata a variável despesa com pessoal, vê se que a média se ampliou e que a variância amostral se reduziu. Esse padrão comportamental é condizente com as análises de Fiovarante e colaboradores (2006), Menezes (2005) e Giuberti (2005), que sugerem que a imposição de $60 \%$ da despesa com pessoal como proporção da receita levaria os municípios, que historicamente vêm se mantendo abaixo deste patamar, a atingi-los.

O comportamento destas variáveis, portanto, sugere que os municípios piauienses parecem vir se equalizando, ou convergindo, para uma situação mais sólida e equiparável com a realidade proposta pela LRF. 


\subsection{Metodologia}

A metodologia de análise aqui empregada é baseada no estudo realizado por De Jesus Macedo e Corbari (2009) para os municípios brasileiros com mais de 100 mil habitantes. Em posse de um painel de dados, esses autores sugerem a seguinte regressão com dados agrupados para se testar o efeito da LRF no endividamento dos municípios:

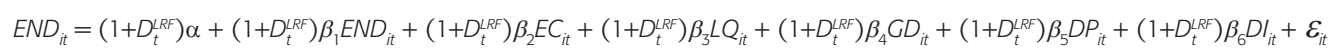

onde $E N D_{i t}$ é o Endividamento Municipal; $E N D_{i t}$ é o Endividamento Defasado; $E C_{i t}$ é a Estrutura de Capital; $L Q_{i t}$ é a Liquidez; $G D_{i t}$ é o Grau de Dependência; $D P_{i t}$ são as Despesas com Pessoal; $D I_{i t}$ são as Despesas com Investimento e; $D_{L R F}$ é a dummy para a Lei de Responsabilidade Fiscal. ${ }^{3}$

De acordo com a tabela 2, os coeficientes estimados neste modelo com painel dinâmico deveriam surtir os seguintes resultados: $\beta_{1}>0$, pois quanto maior o endividamento no passado maior deveria ser o endividamento corrente; $\beta_{2}>0$, pois quanto maior a estrutura de capitais, ou quanto maior o montante de capital de terceiros, maior deveria ser o endividamento; $\beta_{3}<0$, pois quanto maior a liquidez, menor a tendência ao endividamento; $\beta_{4}>$ 0 , pois quanto maior o grau de dependência das outras esferas, maior tende a ser o endividamento e; $\beta_{5}, \beta_{6}>0$, pois quanto maior a despesa com pessoal e investimentos, maior tende a ser o indicador de endividamento.

Vê-se que, no modelo de painel dinâmico proposto por estes autores, a dummy da Lei de Responsabilidade Fiscal entra na regressão de forma aditiva e multiplicativa, sugerindo que a LRF deveria influenciar diretamente a variável dependente e indiretamente, pois a influência das variáveis explanatórias poderia ser diferenciada, de acordo com o período de análise.

No longo prazo, obviamente, a estrutura do endividamento tenderá a se alterar fazendo com que as variáveis preditoras influenciem de maneira diferenciada o endividamento municipal, de acordo com o período em questão. Entretanto, é possível que o período de tempo levado em consideração nesta análise seja relativamente curto para gerar tal diferenciação. Quando isso ocorre, as dummys multiplicativas tendem a ser estatisticamente insignificantes e uma especificação que se ajusta melhor aos dados seria uma especificação que utilizasse a dummy da LRF apenas como uma dummy de intercepto, ou seja:

$$
E N D_{i t}=\alpha_{0}+\alpha_{1} D_{t}^{2 F F}+\beta_{1} E N D_{i t-1}+\beta_{2} E C_{i t}+\beta_{3} L Q_{i t}+\beta_{4} C D_{i t}+\beta_{5} D P_{i t}+\beta_{6} D_{i t}+\eta_{i}+\varepsilon_{i t}
$$

onde as variáveis empregadas e os valores esperados dos coeficientes são os mesmos descritos anteriormente e $\eta_{i}$ representa os efeitos fixos não observáveis das unidades transversais (municípios). ${ }^{4}$

${ }^{3} D_{t}^{L R F}=\left\{\begin{array}{l}0, \text { caso } t \leq 2000 \\ 1 \text {, caso } t>2000\end{array}\right.$

${ }^{4} \mathrm{O}$ controle de painel dinâmico para a heterogeneidade através da utilização de efeitos fixos já foi utilizado por Costa (2008), Santolin e colaboradores (2009) e, de maneira muito rigorosa (estes autores rejeitam o efeito fixo 
As hipóteses adotadas no segundo modelo são: $E\left[\eta_{i}\right]=E\left[\varepsilon_{i t}\right]=E\left[\eta_{i} \varepsilon_{i t}\right]=0$ e $E\left[\varepsilon_{i t} \varepsilon_{i s}\right]=0$ para $i=1,2, \ldots . ., N$ e $\forall t \neq s$. Adicionalmente, existe uma hipótese-padrão relativa às condições iniciais $E N D_{i t}: E\left[E N D_{i t} \varepsilon_{i t}\right]$ para $\mathrm{i}=1,2, \ldots ., \mathrm{N}$ e $\mathrm{t}=1,2, \ldots . ., \mathrm{T}$ (Ahn e Schmidt, 1995).

As técnicas de estimação tradicionais são inapropriadas para a equação (2) devido à presença de efeitos não observáveis das unidades, $\eta_{i}$, em conjunto com a variável dependente defasada, $E N D_{i t-1}$, como variável explicativa.

Do que trata o segundo modelo, omitir os efeitos fixos individuais no modelo dinâmico em painel torna os estimadores de mínimos quadrados ordinários (MQO) tendenciosos e inconsistentes; ou seja, havendo correlação positiva entre a variável dependente defasada e os efeitos fixos, a estimativa do coeficiente $\beta_{1}$ é enviesada para cima (Hsiao, 2004). Por outro lado, o estimador de efeito fixo (EF), que corrige para presença de heterogeneidade nas unidades transversais, gera uma estimativa de $\beta_{1}$ enviesada para baixo em painéis com a dimensão temporal pequena. ${ }^{5}$

Há ainda o problema da provável endogeneidade das variáveis explicativas. Nesse caso, a endogeneidade no lado direito da equação (2) deveria ser tratada através da estimação pelo método dos momentos generalizado em diferenças (MMG-D), para evitar um possível viés gerado por problema de simultaneidade. ${ }^{6}$

No entanto, assumindo que os efeitos fixos e o endividamento passado apresentam correlação positiva, e dada a direção dos vieses discutida anteriormente, um método de estimação apropriado levaria, provavelmente, a uma estimativa entre os coeficientes encontrados ao se utilizar o efeito fixo e os coeficientes encontrados ao se utilizar dados agrupados. Assim, se o valor das estimativas entre estas duas abordagens for relativamente próximo, então as estimativas desses modelos estariam nos informando uma estimativa muito próxima das obtidas por métodos mais sofisticados e apropriados, como as propostas por Arellano e Bond (1991) e Arellano e Bover (1995).

\section{Resultados e discussões}

Foram estimados modelos dinâmicos com dados agrupados e efeito fixo levando em consideração as variáveis dummy de inclinação. Em ambos os casos, a significância estatística destas dummy não se mostrou satisfatória, sugerindo que a especificação (2) seria mais adequada para a análise dos efeitos da LRF sobre o endividamento dos municípios.

em seu modelo, entretanto, realizando uma análise para um nível de significância de apenas 1\%), por Menezes e Corbari (2009).

${ }^{5}$ Através de estudos de Monte Carlo, Judson e Owen (1999) mostram que esse viés pode chegar a 20\%, mesmo em painéis onde $\mathrm{T}=30$.

${ }^{6}$ Ver Arellano-Bond (1991). 
Posto isto, a estimativa para o modelo com dados agrupados é exposta a seguir.

Tabela 4

Estimativas para modelo com dados agrupados

\begin{tabular}{|lcccccc|}
\hline \multicolumn{1}{|c}{ Variável } & Coeficiente & Erro-padrão & Estatística t & \multicolumn{1}{c|}{$\mathrm{p}$-valor } & \multicolumn{2}{c|}{ Intervalo de confiança 95\% } \\
\hline Const & 0.3436 & 0.1086 & 3.160 & 0.002 & 0.1304 & 0.5568 \\
$D_{t}^{\text {LRF }}$ & -0.0669 & 0.0148 & -4.500 & 0.000 & -0.0960 & -0.0377 \\
$E N D_{i t-1}$ & 0.6760 & 0.0215 & 31.460 & 0.000 & 0.6338 & 0.7182 \\
$E C_{i t}$ & -0.0346 & 0.0275 & -1.260 & 0.209 & -0.0887 & 0.0194 \\
$L Q_{i t}$ & -0.0001 & 0.0002 & -0.890 & 0.373 & -0.0004 & 0.0002 \\
$G D_{i t}$ & -0.2564 & 0.0983 & -2.610 & 0.009 & -0.4495 & -0.0634 \\
$D P_{i t}$ & 0.2055 & 0.0602 & 3.410 & 0.001 & 0.0873 & 0.3236 \\
$D I_{i t}$ & 0.3919 & 0.0597 & 6.560 & 0.000 & 0.2747 & 0.5091 \\
\hline $\mathrm{F}(7,739)=185.37$ & & & & & $\mathrm{R} 2=0.6371$ \\
Prob $>\mathrm{F}=0.0000$ & & & & & & R2 Ajustado $=0.6337$ \\
\hline
\end{tabular}

Fonte: Elaboração dos autores.

Os resultados do modelo com dados agrupados revelam que a dummy da LRF é negativa e estatisticamente significante, sugerindo que o índice de endividamento médio dos municípios recuou em aproximadamente $6 \%$, ou seja, a LRF parece ter logrado êxito. No modelo com dados agrupados também se constata que: (i) o Endividamento Defasado é positivo e estatisticamente significante, entretanto, sugerindo uma persistência relativamente baixa, ou seja, o coeficiente estimado de 0,676 parece sugerir que o endividamento municipal não aparenta ser "crônico" e tende a se reverter para a média; ${ }^{7}$ (ii) a Estrutura de Capital e a Liquidez não são estatisticamente significantes; (iii) o coeficiente associado à variável Grau de Dependência não possui o sinal esperado e é estatisticamente significante, sugerindo que quanto maior o grau de dependência, menor o endividamento; (iv) as despesas com pessoal e com investimentos também possuem os sinais esperados (são positivas) e são estatisticamente significantes.

Como salientado, a estimação de modelos dinâmicos sem o devido efeito fixo incorre em estimativas viesadas para cima, enquanto em modelos com efeito fixo o viés é para baixo.

\footnotetext{
${ }^{7}$ Em modelos dinâmicos com estrutura $y_{i t}=\rho y_{i t-1}+\sum \varphi \varepsilon_{i t}$, com $|\rho|<1$, tem-se que os efeitos dos choques vão se diluindo à medida que o tempo vai passando. Isso sugere que ampliações momentâneas do endividamento tendem a convergir para seu valor médio e não se perpetuar indefinidamente. Por conta disso, o endividamento não tende a ser crônico.
} 
Outra questão de interesse refere-se a uma possível correlação serial nos resíduos do modelo estimado. Nesse caso, se tal correlação se fizer presente, os erros-padrão estimados tornam-se enviesados e, como consequência, os estimadores apresentados não seriam eficientes. Para se checar a ausência de autocorrelação serial utilizou-se o teste de Arellano e Bond para um AR(1) e um AR(2) (Roodman, 2006); as respectivas estatísticas z associadas a este teste foram -1,66 e 1,04, com p-valores de 0,097 e 0,2977, o que indica que a hipótese nula de autocorrelação serial deve ser rejeitada para um nível de significância de $5 \%{ }^{8}$

A seguir expõem-se as estimativas para o modelo com efeito fixo.

Tabela 5

Estimativas para modelo com efeito fixo

\begin{tabular}{|c|c|c|c|c|c|c|}
\hline Variável & Coeficiente & Erro-padrão & Estatística t & p-valor & \multicolumn{2}{|c|}{ Intervalo de confiança 95\% } \\
\hline Const & 0.4540 & 0.1225 & 3.710 & 0.000 & 0.2135 & 0.6946 \\
\hline$D_{t}^{L R F}$ & -0.0792 & 0.0148 & -5.350 & 0.000 & -0.1082 & -0.0501 \\
\hline$E N D_{i t-1}$ & 0.5249 & 0.0276 & 19.020 & 0.000 & 0.4707 & 0.5791 \\
\hline$E C_{i t}$ & -0.0237 & 0.0346 & -0.680 & 0.494 & -0.0917 & 0.0443 \\
\hline$L Q_{i t}$ & -0.0001 & 0.0002 & -0.560 & 0.575 & -0.0004 & 0.0002 \\
\hline$G D_{i t}$ & -0.2866 & 0.1117 & -2.570 & 0.011 & -0.5060 & -0.0673 \\
\hline$D P_{i t}$ & 0.1603 & 0.0743 & 2.160 & 0.031 & 0.0144 & 0.3061 \\
\hline$D l_{i t}$ & 0.4534 & 0.0670 & 6.770 & 0.000 & 0.3219 & 0.5850 \\
\hline \multicolumn{3}{|c|}{$F(7,657)=86.04$} & & \multicolumn{2}{|c|}{$R 2$ Within $=0.4783$} & \\
\hline \multicolumn{3}{|c|}{ Prob $>F=0.0000$} & & \multicolumn{2}{|c|}{ R2 Between $=0.9177$} & \\
\hline \multicolumn{3}{|c|}{ Número de Observações $=83$} & & \multicolumn{2}{|c|}{$R 2$ Overall $=0.6295$} & \\
\hline \multicolumn{3}{|c|}{ Obs por grupos: $\min =\max =\operatorname{med}=9$} & & \multicolumn{3}{|c|}{ Teste $F$ para $\eta_{\mathrm{i}}=0, \forall i$} \\
\hline & & & & \multicolumn{2}{|c|}{$F(82,657)=1.55$} & 021 \\
\hline
\end{tabular}

Fonte: Elaboração dos autores.

Em termos dos sinais dos coeficientes e da significância estatística dos mesmos, os resultados do modelo com efeito fixo não diferem muito dos resultados do modelo com dados agrupados. Nossa variável de interesse, a dummy da LRF, $D_{t}^{L R F}$, é negativa e estatisticamente significante, reforçando que o efeito dessa lei beneficiou os municípios em termos de redução

\footnotetext{
${ }^{8}$ Foi utilizado o comando "abar" do Stata. Este teste foi originalmente proposto para um estimador linear para dados em painel dinâmico e, neste caso, é mais indicado que outros comandos como dwstat, durbina, bgodfrey e xtserial (Roodman, 2006).
} 
do endividamento. O coeficiente e o p-valor da referida dummy sugerem uma redução de quase $8 \%$ no endividamento municipal, a partir da data de implementação da LRF.

O teste de correlação serial proposto por Arellano e Bond não é indicado quando há efeitos fixos no painel; nesse caso, um teste mais apropriado seria o proposto por Bera, Sosa-Escudero e Yoon (2001). ${ }^{9}$ O referido teste retorna uma estatística de máxima verossimilhança de 4.45 cujo p-valor é de 0,1083 , o que indica que a hipótese nula de ausência conjunta de autocorrelação e efeito aleatório não deve ser rejeitada. Embora o teste de Baltagi e Li (1995) não rejeite a hipótese de correlação serial (estatística de máxima verossimilhança de 2,08 com p-valor de 0,1491), o ajuste proposto por Bera, Sosa-Escudero e Yoon (2001) retorna uma estatística de teste de 3,99 com p-valor de 0,0458; ou seja, sugere autocorrelação de primeira ordem.

À primeira vista, os resultados dos testes para correlação serial no modelo com efeito fixo parecem conflitantes. Se a autocorrelação não é descartada, então se torna mais indicado estimar um modelo com dados em painel dinâmico; entretanto, mesmo que haja correlação serial, dados os vieses associados aos modelos dinâmicos, as estimativas aqui reportadas indicam que a redução no endividamento municipal possivelmente está entre estes dois valores (o encontrado através do modelo com dados agrupados e o encontrado utilizando-se efeito fixo), ou seja, pode-se afirmar que o efeito real da LRF no endividamento dos municípios piauienses foi entre 6,69 e $7,92 \%$.

\section{Considerações finais}

A busca pela austeridade no Brasil é um fato novo que tem como divisor de águas a introdução da LRF no ano de 2000. Anteriormente a esse período, as administrações públicas eram marcadas pelos sucessivos déficits em que as dívidas eram repassadas para os gestores futuros.

A conjuntura das administrações públicas municipais era pouco favorável à execução de superávits, já que não havia punições objetivas aos maus gestores, criando um ambiente pouco favorável à economicidade, à eficiência e à eficácia na execução dos gastos públicos municipais. Variáveis como despesas com pessoal e gastos com investimentos, por exemplo, eram executados de maneira não planejada, culminando, ao final das administrações, em elevados níveis de endividamento.

Buscando reverter esta situação, foi instituída a LRF. A literatura empírica que trata do efeito dessa lei no endividamento vem ressaltando o caso do Piauí como um dos possíveis, senão o principal beneficiado com tal medida (Fioravante et al., 2006). Este estudo buscou

\footnotetext{
${ }^{9}$ Em posse de um modelo com dados em painel com efeito fixo, o pesquisador usualmente está interessado em testar (i) a hipótese nula de ausência de correlação serial e, (ii) a hipótese nula de ausência de efeito aleatório. Bera, SosaEscudero e Yoon (2001) sugerem aprimoramentos para os testes de Breusch e Pagan (1980) e de Baltagi e Li (1995) que podem ser empregados em modelos deste tipo. Esses testes são sintetizados no comando "xttest1" do Stata.
} 
aprofundar o entendimento desta questão e estimar qual foi o real efeito da lei no endividamento dos municípios piauienses.

As estimativas aqui apresentadas sugerem que (i) as variáveis "estrutura de capital" e "liquidez" não apresentaram significância estatística, ou seja, não parecem influenciar o endividamento dos municípios piauienses; (ii) o "endividamento defasado" parece apresentar persistência relativamente baixa, ou seja, o endividamento municipal parece não ser crônico ou inercial; (iii) o coeficiente associado à variável "grau de dependência" sugere que, quanto maior o grau de dependência, menor o endividamento, ou seja, os municípios parecem vir fazendo bom uso das transferências, podendo, inclusive, estar se capitalizando por meio das mesmas; (iv) A "liquidez" não se mostrou estatisticamente significante, ou seja, não há evidências de que a mesma afete o endividamento dos municípios; (v) as "despesas com pessoal" são capazes de influenciar fortemente o endividamento, entretanto, a influência das "despesas com investimentos" nos municípios piauienses chega a ser de duas a três vezes maior que a influência das "despesas com pessoal".

Visto que existem vieses distintos associados aos coeficientes dos modelos dinâmicos propostos (Judson e Owen, 1999; Hsiao, 2003), mas que esses coeficientes são muito próximos, o estudo sugere que o efeito real da LRF reduziu entre 0,0792 e 0,0669 o endividamento dos municípios piauienses, ou seja, a LRF nesses municípios fez com que a proporção da receita corrente líquida necessária para se cobrir as dívidas tenha se reduzido em, aproximadamente, $7 \%$.

\section{Referências}

AHN, Seung C.; SCHMIDT, Peter. Efficient estimation of models for dynamic panel data. Journal of econometrics, v. 68, n. 1, p. 5-27, 1995.

ARELLANO, Manuel; BOND, Stephen. Some tests of specification for panel data: Monte Carlo evidence and an application to employment equations. The Review of Economic Studies, v. 58, n. 2, p. 277-297, 1991.

ARELLANO, Manuel; BOVER, Olympia. Another look at the instrumental variable estimation of error-components models. Journal of econometrics, v. 68, n. 1, p. 29-51, 1995.

BALTAGI, Badi H.; LI, Qi. Testing AR(1) against MA(1) disturbances in an error component model. Journal of Econometrics, v. 68, n. 1, p. 133-151, 1995.

BERA, Anil K.; SOSA-ESCUDERO, Walter; YOON, Mann. Tests for the error component model in the presence of local misspecification. Journal of Econometrics, v. 101, n. 1, p. 1-23, 2001.

BREUSCH, Trevor S.; PAGAN, Adrian R. The LM test and its applications to model specification in econometrics. Review of Economics Studies, v. 47, n. 1, p. 239-254, 1980.

COSTA, José F. Reflexos da Lei de Responsabilidade Fiscal no endividamento dos municípios brasileiros. In: CONGRESSO BRASILEIRO DE CONTABILIDADE, 18ㅇ, 24-28 ago. 2008, Gramado. Anais dos trabalhos científicos. Disponível em: <www.congressocfc.org.br/hotsite/trabalhos_1/334.pdf > . Acesso em: 10 jun. 2012. 
DE JESUS MACEDO, Joel; CORBARI, Ely Célia. Efeitos da Lei de Responsabilidade Fiscal no endividamento dos municípios brasileiros: uma análise de dados em painéis. Revista Contabilidade \& Finanças-USP, v. 20, n. 51, p. 44-60, 2009.

FIORAVANTE, Dea G. et al. Lei de Responsabilidade Fiscal e finanças públicas municipais: impactos sobre despesas com pessoal e endividamento. Ipea, 2006. (Texto para Discussão, n. 1223).

FIORAVANTE, Dea G.; PINHEIRO, Maurício S.; VIEIRA, Roberta S. Finanças públicas municipais: uma reflexão sobre os impactos da Lei de Responsabilidade Fiscal. In: CARVALHO, Alexandre Xavier Ywata et al. (Org.). Dinâmica dos municípios. Brasília: IPEA, 2008. v. 1, p. 53-112.

GIUBERTI, Ana C. Efeitos da Lei de Responsabilidade Fiscal sobre os gastos dos municípios brasileiros. Dissertação (mestrado em economia) - Faculdade de Economia, Administração e Contabilidade, Universidade de São Paulo, São Paulo, 2005.

HSIAO, Cheng. Analysis of panel data. Cambridge: Cambridge University Press, 2003.

JUDSON, Ruth A.; OWEN, Ann L. Estimating dynamic panel data models: a guide for macroeconomists. Economics Letters, v. 65, n. 1, p. 9-15, 1999.

MATIAS, Alberto B.; CAMPELLO, Carlos Alberto G. B. Administração financeira municipal. São Paulo: Atlas, 2000.

MENEZES, Rafael T. Impactos da Lei de Responsabilidade Fiscal sobre os componentes de despesas dos municípios brasileiros. Finanças públicas: XI Prêmio Tesouro Nacional - 2005. In: Coletânea de monografias, 2006. p. 747-801.

ROODMAN, David. How to do xtabond2: an introduction to difference and system GMM in Stata. Center for Global Development working paper, n. 103, 2006.

SANTOLIN, Roberto; JAYME JR., Frederico Gonzaga; REIS, Júlio César dos. Lei de Responsabilidade Fiscal e implicações na despesa de pessoal e de investimento nos municípios mineiros: um estudo com dados em painel dinâmico. Estudos Econômicos, São Paulo, v. 39, n. 4, p. 895-923, 2009.

VELOSO, Gilberto O.; TEIXEIRA, Anderson M. A Lei de Responsabilidade Fiscal e as microrregiões do estado do Rio Grande do Sul: uma análise empírica. Ensaios FEE, Porto Alegre, v. 28, n. 2, p. 443-470, out. 2007. Disponível em: <www.stn.fazenda.gov.br>. Acesso em: 5 abr. 2010.

Fabricio Linhares é $\mathrm{PhD}$ em economia pela University of New Hampshire e professor do Centro de Aperfeiçoamento de Economistas do Nordeste (Caen) da Universidade Federal do Ceará (UFC). E-mail: flinhares@caen.ufc.br.

Christiano Penna é doutor em economia pelo Centro de Aperfeiçoamento de Economistas do Nordeste (Caen) e professor do Departamento de Teoria Econômica da Universidade Federal do Ceará (UFC). E-mail: cmp@caen.ufc.br.

Glenda Borges é mestre em economia pelo Centro de Aperfeiçoamento de Economistas do Nordeste (Caen) da Universidade Federal do Ceará (UFC) e professora da Faculdade Evangélica do Piauí (Faepi). E-mail: glendaborges7@hotmail.com. 
